\title{
Antimicrobial activity of the trans-cinnamaldehyde on nosocomial enteric bacilli producers of extended spectrum $\beta$-lactamase (ESBL)
}

\author{
Vicente Pinto ${ }^{1 *}$, César Barbosa ${ }^{2}$, Pedro Magalhães ${ }^{3}$, Camila Coelho $^{4}$, Joseires Fontenelle ${ }^{5}$, Gerardo Cristino-Filho ${ }^{1}$, \\ Helliada Chaves ${ }^{2}$, Antonio Silva², Alrieta Teixeira², Mirna Bezerra ${ }^{1}$
}

From 5th Congress of the Brazilian Biotechnology Society (SBBIOTEC)

Florianópolis, Brazil. 10-14 November 2013

\section{Background}

The extended spectrum $ß$-lactamases (ESBL) are enzymes that produce resistance to ß-lactam antibiotics, including penicillins, wide spectrum cephalosporins and aztreonam, by cleavage of $\beta$-lactam ring (BUSH \& JACOBY, 2010). Since ESBL-producing bacteria are frequently associated with nosocomial infections, treatment options are becoming increasingly limited (RAWAT \& NAIR, 2010). In this context, the discovery of compounds which can inhibit the growth of micro-organisms which produce these enzymes becomes increasingly important.

\section{Methods}

In this study were evaluated the antimicrobial activity of trans-cinnamaldehyde by microdilution technique and also determined its minimum bactericidal concentration $(\mathrm{MBC})$ on nosocomial enteric bacilli ß-lactamases producers. We analyzed 45 bacterial species, 36 to the Enterobacteriaceae family and nine of the other species of Gram-negative bacteria. The most prevalent species ESBL-producing was Klebsiella pneumoniaessp. pneumoniae (70\% of isolates of this specie). The detection of ESBL was performed by phenotypic testing (approximation discs, combination discs and minimum inhibitory concentration - MIC - using E-test).

\section{Results and conclusions}

The trans-cinnamaldehyde showed antibacterial activity and promote inhibition of growth for all planktonic microorganisms ESBL positive tested, with MIC ranging between $0.95 \mathrm{mM}$ and $1.90 \mathrm{mM}$. Bactericidal activity was detected at a concentration of $1.90 \mathrm{mM}$, regardless of the species analyzed in this study. Our results suggest that trans-cinnamaldehyde is a compound with potential antimicrobial against ESBL-producing bacteria and can be employed both in preventing infection through their application in solutions used in the processes of disinfection of hospital instruments and equipment but also in drug development for topical action.

\begin{abstract}
Authors' details
${ }^{1}$ Faculty of Medicine of Sobral, Master's Program in Biotechnology, Federal University of Ceará (UFC), Campus-Sobral, Ceará, Brazil. ${ }^{2}$ Faculty of Dentistry of Sobral, Federal University of Ceará (UFC), Campus-Sobral, Ceará, Brazil. ${ }^{3}$ Department of Physiology and Pharmacology, Faculty of Medicine, Federal University of Ceará (UFC), Fortaleza, Ceará, Brazil. ${ }^{4}$ Faculty of Medicine of Sobral,Federal University of Ceará (UFC), Campus-Sobral, Ceará, Brazil. ${ }^{5}$ Masters in Biotechnology, Federal University of Ceará (UFC), Campus-Sobral, Ceará, Brazil.
\end{abstract}

Published: 1 October 2014

\section{References}

1. Bush K, Jacoby GA: Updated functional classification of $\beta$-lactamases. Antimicrob Agents Chemother 2010, 54(3):969-976.

2. Rawat $D$, Nair $D$ : Extended-spectrum $\beta$-lactamases in gram negative bacteria. J Glob infect dis 2010, 2(4):263-274.

\section{doi:10.1186/1753-6561-8-S4-P89}

Cite this article as: Pinto et al: Antimicrobial activity of the transcinnamaldehyde on nosocomial enteric bacilli producers of extended spectrum $\beta$-lactamase (ESBL). BMC Proceedings 2014 8(Suppl 4):P89. 